\title{
Implicit vs. explicit deception in ultimatum games with incomplete information
}

\author{
Kriss, Peter H ; Nagel, Rosmarie ; Weber, Roberto A
}

\begin{abstract}
We explore bargaining, using ultimatum games, when one party, the proposer, possesses private information about the pie size and can either misrepresent this information through untruthful statements (explicit deception) or through information-revealing actions (implicit deception). Our study is the first such direct comparison between two ways in which people can deceive. We find that requiring informed parties to make an explicit statement yields greater deception than when information is communicated implicitly, particularly for larger stakes. However, allowing the explicit statement to be accompanied by a promise of truthfulness reverses this effect. In contrast with many previous studies, we generally observe very high frequencies of dishonesty.
\end{abstract}

DOI: https://doi.org/10.1016/j.jebo.2013.03.024

Posted at the Zurich Open Repository and Archive, University of Zurich ZORA URL: https://doi.org/10.5167/uzh-70883

Journal Article

Originally published at:

Kriss, Peter H; Nagel, Rosmarie; Weber, Roberto A (2013). Implicit vs. explicit deception in ultimatum games with incomplete information. Journal of Economic Behavior and Organization, 93:337-346.

DOI: https://doi.org/10.1016/j.jebo.2013.03.024 


\title{
Implicit vs. Explicit Deception in Ultimatum Games with Incomplete Information
}

\author{
Peter H. Kriss (Medallia, Inc.) \\ Rosemarie Nagel (Universitat Pompeu Fabra) \\ Roberto A. Weber (University of Zurich)
}

January 10, 2013*

\begin{abstract}
We explore bargaining, using ultimatum games, when one party, the proposer, possesses private information about the pie size and can either misrepresent this information through untruthful statements (explicit deception) or through informationrevealing actions (implicit deception). Our study is the first such direct comparison between two ways in which people can deceive. We find that requiring informed parties to make an explicit statement yields greater deception than when information is communicated implicitly, particularly for larger stakes. However, allowing the explicit statement to be accompanied by a promise of truthfulness reverses this effect. In contrast with many previous studies, we generally observe very high frequencies of dishonesty.
\end{abstract}

\footnotetext{
* We thank the Pittsburgh Experimental Economics Laboratory (PEEL) for access to their laboratory resources and John Hamman for valuable research assistance. Weber gratefully acknowledges support from the Research Priority Program, "Foundations of Human Social Behavior," at the University of Zurich. Nagel thanks the Spanish Ministry of Education (SEJ2005-08391 and ECO2008-01768), Barcelona Graduate School of Economics, and the Generalitat de Catalunya.
} 


\section{Introduction}

Considerable work in behavioral economics explores strategic situations involving asymmetric information, in which one party can deceive the other (see for instance, Croson, et al., 2003, Gneezy 2005; Charness and Dufwenberg, 2006), producing the overall result that most players do not lie. Such truth telling has typically been interpreted as ethical behavior (see e.g. Brandts \& Charness, 2003). ${ }^{1}$

Bargaining often contains informational asymmetries, opening doors for deception. For example, in employer-employee wage bargaining the employer can benefit by strategically misrepresenting the employee's contribution. While there is an abundant experimental literature on bargaining with complete information about relevant game parameters, addressing mainly issues of social preferences, there are fewer papers examining bargaining under incomplete information. ${ }^{2}$

We study deception in a simple (ultimatum) bargaining game with (one-sided) asymmetric information about the allocation over which the parties bargain (e.g., Mitzkewitz and Nagel, 1993; Güth, Huck, and Ockenfels, 1996; Kagel et al.,1996). Our focus is on comparing different ways proposers can misrepresent information. In particular, we compare explicit deception, whereby proposers explicitly communicate the drawn allocation together with the offer, to implicit deception, whereby proposers convey such information solely through offers. While explicit and implicit deception have been studied separately in bargaining games (e.g., Boles, et al., 2000; Mitzkewitz and Nagel, 1993), no prior study presents a direct comparison.

We conduct a laboratory experiment using an ultimatum game in which the size of the allocation $(w)$ can vary between a low amount, $w_{L}$, and a high amount, $w_{H}$, with equal probability - i.e., $\mathrm{p}\left(w=w_{L}\right)=\mathrm{p}\left(w=w_{H}\right)=0.5$. The proposer is informed of the allocation, while the responder knows nothing beyond the prior. The proposer then makes an offer contingent on the allocation, $x(w), 0 \leq x \leq w$, which the responder either accepts or rejects. If we let $a$ denote the responder's decision to accept $(a=1)$ or reject $(a=0)$, the proposer's payoff is $\pi_{P}=a(w-x)$, while the responder's payoff is $\pi_{R}=a x$.

\footnotetext{
${ }^{1}$ Neurological data suggest that lying requires both a moral disinhibition and the cognitive ability to keep track of untrue statements (Yang, et al., 2005). Thus, the determinants of lying may be more complicated than of simple moral preferences.

2 Tingley and Wang (2010) review the literature on sequential bargaining with one- or two-sided incomplete information and Croson et al. (2003) on one- and two-sided incomplete information in ultimatum games. Several theoretical papers on bargaining with incomplete information focus on mechanisms to achieve efficiency (e.g., Sanchez-Pages, 2011; Ausubel, Cramton, and Deneckere, 2002).
} 
In such situations, responders averse to unfavorable inequality (e.g., Fehr and Schmidt, 1999) may be unable to perceive the inequality that results from a particular offer, due to the informational asymmetry. Thus, a proposer who draws a large allocation can obtain higher payoffs when the responder believes that the allocation may be small, by making uninformative offers that convey no information. Additionally, with explicit lying, the proposer can send uninformative "small pie" messages regardless of the allocation size. Therefore, explicit deception involves a misleading or an unambiguously false statement in addition to the information conveyed, implicitly, through an uninformative offer. For the purposes of deceiving the responder, this additional step is strategically irrelevant, since it requires only sending an additional uninformative message.

However, there are reasons to believe that behavior and outcomes may differ when proposers deceive implicitly compared with when they must do so explicitly. For instance, prior research on deception and dishonesty shows that people will often forgo making explicitly false statements, as if they experience an internal psychological cost to lying (Gibson, Tanner, and Wagner, 2012; Gneezy, 2005; Charness and Dufwenberg, 2006). Thus, even if the ability to deceive and the monetary gain from doing so are equivalent between situations involving explicit and implicit deception, the willingness to deceive may be lower with explicit deception.

Another way in which behavior and outcomes may differ when deception is explicit versus implicit is in the response of the party being deceived. For example, if the responder in the ultimatum game is convinced more easily that the allocation is small when also receiving a deceptive message than when solely receiving a small offer, the potential benefit from acting deceptively for the proposer can also be greater. Thus, proposers may find it easier to mislead responders when they do so explicitly, rather than implicitly.

Our experiment compares bargaining behavior and outcomes across conditions involving explicit and implicit deception. We particularly focus on offers under $w_{L}$ and $w_{H}$ allocations in each condition. We study the difference between offers for the two allocations, as a measure of the informativeness of offers regarding the actual allocation. As another measure of deceptive proposals, we study the percentage of offers that are greater than half of the small allocation, as these send a strong signal that the allocation is large. We also study whether (small) offers are accepted, implying successful deception, differentially across conditions. Finally, we vary the size of the large 
allocation to explore whether the willingness to deceive, implicitly or explicitly, is affected by the potential monetary gains from doing so.

\section{Experimental Design}

Sessions took place at the Pittsburgh Experimental Economics Laboratory (PEEL) at the University of Pittsburgh using the software $z$-tree (Fischbacher, 2007). For each session, 16 participants were recruited via e-mail from the student populations of the University of Pittsburgh and Carnegie Mellon University.

At the beginning of a session, participants drew cards with letters " $\mathrm{A}$ " (proposer) and "B" (responder), and were seated separately by roles. They received written instructions read aloud by the experimenter.

In each of six experimental conditions the basic two-player ultimatum game with asymmetric information described earlier was repeated for 10 rounds with random rematching and no pairing repeated in consecutive rounds. In every round one of two possible allocations, $w_{H}$ and $w_{L}$, was drawn with equal probability. The proposer alone observed the draw $(w)$ and then made an offer, in ten-cent increments between $\$ 0$ and $w$, to the responder, who either accepted or rejected this proposal. Payoffs were as described earlier. The true allocations were never revealed to responders, to reduce the detection of lying. At the end of the experiment, the software selected one round at random for payment, additional to a $\$ 6$ participation fee.

Our main treatment varies the channels available to the proposer for communicating about the allocation. A No Message condition (implicit deception) proceeded as above. Our experiment also included two explicit deception conditions. In a Message condition, the proposer sent a message corresponding to one of the two possible values of $w$-i.e., " $w_{L}$ " or " $w_{H}$ " - to the responder, along with the offer. A Message \& Promise condition further added the possibility of sending a promise that the message was true. This (seemingly trivial) opportunity may increase the psychological costs to lying for proposers relative to simply sending deceptive messages or may increase the willingness of responders to believe deceptive messages.

The small allocation $\left(w_{L}\right)$ was always $\$ 10$ while the large allocation $\left(w_{H}\right)$ varied. In a High Stakes condition it was \$20, while in a Low Stakes condition it was \$14.

The experiment therefore consisted of six conditions, 3 (No Message; Message; Message \& Promise) X 2 (High Stakes, Low Stakes). Each subject participated in only one condition. 
Following the final round, participants completed two questionnaires measuring a propensity to engage in unethical behavior for personal gains, the Mach-IV test of Machiavellianism (Christie and Geis, 1970) and the Self-Reported Inappropriate Negotiations Strategies scale (SINS) (Robinson, Lewicki, and Donahue, 2000). The experiment then concluded with payment.

\section{Results}

We conducted a total of 18 sessions, 3 for each condition, with a total of 288 participants, 144 in the role of proposer. Our analysis focuses on testing the null hypothesis that behavior and outcomes do not differ between the three message conditions, across which the ability to deceive is theoretically identical.

\section{Offers}

Figure 1 shows the average offers across time, separately for low $\left(w_{L}\right)$ and high allocations $\left(w_{H}\right)$ in each condition, with High (Low) Stakes conditions in the top (bottom) panels. To lessen variation due to idiosyncratic subject behavior interacting with random allocation draws, we pool across two-period blocks.

\section{(Insert Figure 1 here)}

First, we consider whether the difference between offers for low and high allocations, a measure of the informativeness of offers, differs across conditions. Smallallocation offers are roughly the same in all conditions. However, the gap with offers under high allocations is smallest in the middle column, the Message condition, and roughly equally large for No Message (left) and Message and Promise (right).

\section{(Insert Table 1 here)}

This pattern is confirmed in the regressions reported in Table 1, which test, separately for the High and Low stakes conditions, the effects of message conditions on offers, including subject-level random effects and clustering of standard errors. The constant term measures the size of small-allocation offers in the No Message condition. Consistent with prior research, mean offers are generally slightly below half of the small 
allocation. The additional effect for the Message and Message \& Promise conditions, measured by the respective coefficients, are not statistically significant.

In the No Message condition, high-allocation offers are significantly higher than those for low allocations, by about $\$ 1.90$ and $\$ 0.49$, respectively, for High and Low stakes. Thus, when implicit deception is possible, proposers do not fully exploit their informational advantage by making entirely uninformative offers. Instead, proposers offered, on average, between 12 and 19 percent of the additional surplus of a high allocation.

The coefficients on Allocation High X Message Conditions are negative, and statistically significant for high stakes. This confirms our observation from Figure 1 of smaller offer difference between low and high allocations with explicit messages.

Adding promises creates another reversal, in the direction of less deception. The coefficients for Allocation High X Message \& Promise Condition - which capture the marginal effect of adding promises to the Message Condition - are positive and statistically significant, consistent with an interpretation of increased lying costs for explicit deception when promises are possible.

We can also explore differences between high- and low-allocation offers at the individual subject level. Figures $2 \mathrm{~A}$ and $2 \mathrm{~B}$ present each proposer's average offers across rounds, separately for small (\$10, $\mathrm{x}$-axis) and large allocations ( $\$ 20$ or $\$ 14, \mathrm{y}$ axis), for the High and Low Stakes conditions. The different markers indicate the message conditions.

\section{(Insert Figures $2 A$ and $2 B$ here)}

The figures show, first, that many observations are clustered around the midpoint of $\$ 5$ for both allocations, corresponding to cases in which proposers offered half of the small allocation, regardless of the actual allocation size. Second, where observations depart from the 45-degree line, they tend to be above it, corresponding to proposers making higher offers when the allocation is high than when it is low and thus potentially conveying information to responders about the actual allocation size.

Third, departures from the diagonal tend to be larger and more frequent in the No Message and Message \& Promise conditions than in the Message condition. This confirms what we found earlier. Offers are less informative when they are accompanied by a message than when they are not and than when the message can include a promise. 
In the On-line Appendix, we present further evidence that, at the level of individual behavior, high- and low-allocation offer differences are greater in the No Message and Message \& Promise conditions. ${ }^{3}$ We also show that individual personality differences measured using psychometric scales predict the willingness of proposers to act deceptively by making uninformative offers. ${ }^{4}$

Our analysis thus far uses differences between high- and low-allocation offers, i.e., a measure of how informative offers are about allocations, to identify the extent to which proposers behave deceptively across conditions. However, we can also test the extent to which we find similar results using other measures. To this end, we compare the frequency of high-allocation offers that are strictly greater than $\$ 5$ as an alternative measure of non-deceptive behavior. Since offers of half the allocation are equitable and rarely rejected in ultimatum games (e.g., Camerer, 2003, Chapter 2), offers above onehalf of the small allocation can be interpreted as sending the responder clear information that the allocation must be above $\$ 10\left(w_{L}\right)$. By this measure, we again observe more "honest" behavior in the No Message and Message \& Promise conditions (30 and 31 percent, respectively) than in the Message condition (16 percent).

\section{Messages \& Promises}

We next study the frequency with which proposers engaged in explicit deception in the conditions with messages. Figure 3 presents the frequencies of honest and dishonest messages and promises across the two Message conditions for cases in which the allocation was high (low allocations are omitted as corresponding messages were overwhelmingly honest). Honest messages are twice as frequent in the Message \& Promise condition as in the Message condition. The proportion of subjects who send dishonest messages accompanied by promises ( 65 percent) is lower than those who send dishonest messages in the Message condition (89 percent). This is consistent with our earlier inference, based on offers, that dishonest behavior is less frequent when promises are possible than when they are not.

\footnotetext{
${ }^{3}$ For example, we look at all the offers made by individual proposers, and classify subjects according to whether their high- and low-allocation offer differences are statistically detectable. Roughly five times as many proposers make informative offers, according to this criterion, in the No Message and Message \& Promise conditions as in the Message condition.

${ }^{4}$ Specifically, proposers who rate dishonest negotiation tactics as less appropriate, using the Self-

Reported Inappropriate Negotiations Strategies (SINS) survey (Robinson, et al., 2000), also tend to exhibit greater large- vs. small-allocation offer differences, particularly in the No Message and Message $\&$ Promise conditions.
} 
Figure 4 shows the mean offers, by message, condition, and stake size. Offers are clearly higher after a "High" message than after a "Low" message, and each such pairwise comparison is statistically significant. ${ }^{5}$

Importantly, there are also no differences in offers, conditional on the message sent, between the Message or Message \& Promise conditions. That is, the first and third bars are equal, as are the second and fourth bar, etc., with no significant difference in any such pairwise comparisons. Thus the earlier observation of offer differences between the two message conditions comes from the additional deception in the Message condition.

\section{Rejections}

Figures 5A (High Stakes) and 5B (Low Stakes) show rejection rates for different offer ranges, by message condition. ${ }^{6}$ Offers of $\$ 4$ or less are rejected most frequently in the No Message conditions and least frequently in the Message \& Promise conditions. For higher offers, rejections fall considerably with only small differences across conditions. Table 2 presents (subject) random-effects probit regressions of rejections, using offer and conditions as explanatory variables. We find a negative and significant offer coefficient. Also, rejections are significantly less frequent in the Message \& Promise condition for low offers, but the difference diminishes as offers increase (i.e., the interaction between offer and Message \& Promise condition is positive).

(Insert Figures $5 A$ and $5 B$ and Table 2 here)

Interestingly, rejection rates in the Message \& Promise condition do not differ significantly depending on whether or not a promise was made. For example, offers between $\$ 0$ and $\$ 4$ that follow a message claiming a small allocation $\left(w_{L}\right)$ are rejected 35 percent of the time with a promise and 31 percent of the time without one. Thus, the possibility of using promises, rather than their actual use, appears to decrease the

\footnotetext{
${ }^{5}$ We conduct regressions of offer on message, for each message condition and stake size and with subject-level random effects and standard errors clustered by subject. In each case, the coefficient on message equals "High" is positive and statistically significant at $\mathrm{p}<0.01$.

${ }^{6}$ The categories were determined by finding the smallest range for which each of the six conditions had at least 20 offers. The resulting classification relies on whole dollar amounts due to the high frequencies of offers at these points.
} 
frequency of rejections. This is also supported by models 2 and 4 in Table 2, which including binary variables for whether a promise was made); the introduction of this variable is largely inconsequential.

\section{Earnings}

Finally, we consider how earnings differed by condition. Figure 6 presents proposers' average earnings by condition. For both High and Low stakes, proposers earn the most money in the Message condition, when they can send messages without the option of a promise. This is consistent with our earlier observation that deception is highest in the Message condition.

Table 3 reports (subject) random-effects regressions of earnings. As models 1 and 4 reveal, the above difference is statistically significant in the Low stakes conditions, but not in the High stakes conditions.

Models 2 and 5 add a variable identifying allocation size, and interact it with condition. Not surprisingly, proposers earn more when the allocation is high. Moreover, the interactions reveal that proposers earn more from high allocations when they can send messages, and less when the messages can include promises, but these effects are not always statistically significant.

Finally, models 3 and 6 include a proposer's SINS score (Robinson, et al., 2000), a psychological survey-based measure of willingness to engage in deceptive behavior in negotiations, and its interaction with whether the allocation is high. Consistent with analysis in the On-line Appendix, proposers who score higher on the SINS scale benefit from more strategic offers and earn more of the high allocation. ${ }^{7}$

\section{Discussion and Conclusion}

Our paper studies implicit and explicit deception in bargaining situations with asymmetric information. From a standard game theoretic perspective, a proposer's strategic ability to deceive a responder is equivalent, regardless of whether proposers can send messages or make promises. When proposers act deceptively, offers, messages and promises are all uninformative. Our study explores whether, for psychological

\footnotetext{
${ }^{7}$ The On-line Appendix reports corresponding analyses for responder earnings. The results generally show a consistent, and inverted, pattern. For example, responders earn less of the high allocation in the Message condition, but more when promises are possible. However, the treatment effects on responder earnings are generally weaker than for proposers.
} 
reasons, these distinct ways of engaging in deception may result in different behaviors and bargaining outcomes.

Our results clearly reject the null hypothesis of no difference between the different communication conditions. Providing the opportunity to send a promise leads to less dishonest messages and more informative offers. Thus, the opportunity to make promises likely increases the psychological cost of lying and thereby mitigates dishonest behavior.

However, when comparing a situation in which deception is done through actions alone (implicit deception, in the No Message condition) with one in which it is done through actions and messages (explicit deception, in the Message condition), there is significantly greater misrepresentation in the latter. That is, our proposers find it psychologically easier to make deceptive offers when they send messages without the opportunity to make promises. The result is that the condition in which they send messages alone is the most profitable for proposers in that it allows them to capture the greater share of surplus produced by high allocations.

We also find that a scale, used in psychological and negotiations research, to measure a willingness to act dishonestly in bargaining contexts has predictive power for identifying which proposers are willing to use their strategic advantage to act deceptively and to obtain higher earnings. This suggests that such scales might be a valuable complement to choice data in identifying which individuals are likely to respond to behavioral contextual influences.

We also observe that responders react differently to different kinds of potential deception. In particular, they reject low offers less frequently in conditions in which proposers can make promises, even when such promises are not actually made.

While our work leaves open the precise psychological mechanisms that drive the behavioral differences across conditions, we make an important contribution by showing that even when holding informational asymmetry constant, the type of deception opportunities available can be important in determining whether one ultimately acts dishonestly. ${ }^{8}$ Thus, consistent with other research in behavioral economics we show that how one gets to an outcome can be as important as the outcome itself, particularly in the extent to which it triggers different norms of what is

\footnotetext{
${ }^{8}$ This result has some similarities with the findings of Cain et al. (2005), who show that disclosing conflicts of interest allows conflicted advisors to feel more licensed to provide self-serving advice. In both cases, the ability to disclose information makes it easier for individuals to act unfairly.
} 
and is not appropriate behavior (e.g., Brandts and Sola, 2001; Krupka and Weber, forthcoming; Gino et al., forthcoming).

\section{References}

Ausubel, L. M., Cramton, P., Deneckere, R. J., 2002. Bargaining with Incomplete Information. In: Aumann, R. J., Hart, S. (Eds.), Handbook of Game Theory, Vol. 3. Elsevier Science B.V., Amserdam, chapter 50.

Boles, T. L., Croson, R. T. A., Murninghan, J. K., 2000. Deception and Retribution in Repeated Ultimatum Bargaining. Organizational Behavior and Human Decision Processes 83(2), 235-259.

Brandts, J., Charness, G., 2003. Truth or consequences: An experiment. Management Science 49(1), 116-130.

Brandts, J., Sola, C., 2001. Reference points and negative reciprocity in simple sequential games. Games and Economic Behavior 36(3), 138-157.

Cain, D. M., Loewenstein, G., Moore, D. A., 2005. The dirt on coming clean: Perverse effects of disclosing conflicts of interest. Journal of Legal Studies 34, 1-24.

Camerer, C. F., 2003. Behavioral Game Theory: Experiments in Strategic Interaction. Princeton University Press, Princeton, NJ.

Charness, G., Dufwenberg, M., 2006. Promises and Partnership. Econometrica 74(6), 1579-1601.

Christie, R., Geis, F., 1970. Studies in Machiavellianism. Academic Press.

Croson, R., Boles, T., Murnighan, J.K., 2003. Cheap talk in bargaining experiments: lying and threats in ultimatum games. Journal of Economic Behavior and Organization 51(2), 143-159.

Fehr, E., Schmidt, K.M., 1999. A Theory of Fairness, Competition, and Cooperation. The Quarterly Journal of Economics 114(3), 817-868.

Fischbacher, U., 2007. z-Tree: Zurich Toolbox for Ready-made Economic Experiments. Experimental Economics 10(2), 171-178.

Gibson, R., Tanner, C., Wagner, A. F., 2012. Preferences for Truthfulness: Heterogeneity Among and Within Individuals. SSRN eLibrary (April 10). http://papers.ssrn.com/sol3/papers.cfm?abstract_id=1323283.

Gino, F., Krupka, E., Weber. R. A. forthcoming. License to cheat: Voluntary regulation and ethical behavior. Management Science.

Gneezy, U., 2005. Deception: The Role of Consequences. The American Economic Review 95 (1), 384-394.

Güth, W., Huck, S., Ockenfels, P., 1996. Two-Level Ultimatum Bargaining with Incomplete Information: An Experimental Study. The Economic Journal 106 (436),593-604.

Kagel, J. H., Kim, C., Moser, D., 1996. Fairness in ultimatum games with asymmetric information and asymmetric payoffs. Games and Economic Behavior 13, 100110. 
Krupka, E., Weber, R.A., forthcoming. Why does dictator game sharing vary? Identifying social norms using coordination games. Journal of the European Economic Association.

Mitzkewitz, M., Nagel, R., 1993. Experimental Results on Ultimatum Games with Incomplete Information. International Journal of Game Theory 22(2), 171-198.

Ockenfels, A., Selten, R., 2000. An Experiment on the Hypothesis of Involuntary TruthSignalling in Bargaining. Games and Economic Behavior 33(1), 90-116.

Rapoport, A., Sundali, J., Seale, D. A., 1996. Ultimatums in two-person bargaining with one-sided uncertainty: Demand games. Journal of Economic Behavior and Organization 30, 173-196.

Robinson, R. J., Lewicki, R. J., Donahue, E.M., 2000. Extending and Testing a Five Factor Model of Ethical and Unethical Bargaining Tactics: Introducing the SINS Scale. Journal of Organizational Behavior 21(6), 649-664.

Sanchez-Pages, S., 2011. Bargaining and Conflict with Incomplete Information. In: Garfinkel, M. R., Skaperdas, S. (Eds.), Oxford Handbook of the Economics of Peace and Conflict, Oxford University Press, Oxford, chapter 4.

Tingley, D. H., Wang, S. W., 2010. Belief Updating in Sequential Games of Two-Sided Incomplete Information: An Experimental Study of a Crisis Bargaining Model. Quarterly Journal of Political Science 5(3), 243-255

Yang, Y., Raine, A. Lencz, T. Bihrle, S. Lacasse, L. 2005. Prefrontal white matter in pathological liars. British Journal of Psychiatry, 187, 320-325. 
Table 1. Regressions of offers on condition

\begin{tabular}{lcc}
\hline Dependent variable: offer & $\begin{array}{c}(1) \\
\text { High Stakes } \\
(\$ 10 / \$ 20)\end{array}$ & $\begin{array}{c}(2) \\
\text { Low Stakes } \\
(\$ 10 / \$ 14)\end{array}$ \\
\hline Message Conditions & 0.388 & 0.056 \\
& $(0.258)$ & $(0.205)$ \\
Message \& Promise Condition & -0.255 & -0.257 \\
& $(0.169)$ & $(0.230)$ \\
Allocation High $\left(w_{H}\right)$ & $1.917^{* * *}$ & $0.494^{* * *}$ \\
Allocation High & $(0.375)$ & $(0.233)$ \\
X Message Conditions & $-1.203^{* * *}$ & -0.254 \\
Allocation High & $(0.416)$ & $(0.261)$ \\
X Message \& Promise Condition & $0.677^{* * *}$ & $0.565^{* * *}$ \\
Period & $(0.352)$ & $(0.206)$ \\
& 0.026 & -0.034 \\
Constant & $(0.025)$ & $(0.026)$ \\
$\mathrm{R}^{2}$ & $4.203^{* * *}$ & $4.780^{* * *}$ \\
Observations & $(0.292)$ & $(0.216)$ \\
Number of subjects & 0.170 & 0.056 \\
\hline
\end{tabular}

Data from proposers only

Includes (subject) random effects; robust standard errors (clustered by subject) in parentheses $* * * \mathrm{p}<0.1, * * \mathrm{p}<0.05, * \mathrm{p}<0.01$ 
Table 2. Probit regressions of rejection decisions

Dependent variable:

(1)

(2)

(3)

(4)

Offer rejected

High Stakes $(\$ 10 / \$ 20) \quad$ Low Stakes $(\$ 10 / \$ 14)$

\begin{tabular}{lcccc}
\hline Offer & $-1.227^{* * *}$ & $-1.228^{* * *}$ & $-1.507^{* * *}$ & $-1.502^{* * *}$ \\
& $(0.212)$ & $(0.212)$ & $(0.228)$ & $(0.227)$ \\
Message Condition & -0.0270 & -0.0277 & -0.816 & -0.804 \\
& $(1.244)$ & $(1.244)$ & $(1.239)$ & $(1.236)$ \\
Message \& Promise Condition & $-3.995^{* * *}$ & $-4.079^{* * *}$ & $-3.903^{* * *}$ & $-3.712^{* * *}$ \\
& $(1.104)$ & $(1.141)$ & $(0.990)$ & $(1.040)$ \\
Offer X & 0.0354 & 0.0356 & 0.199 & 0.196 \\
Message Condition & $(0.272)$ & $(0.272)$ & $(0.283)$ & $(0.282)$ \\
Offer X & $0.841^{* * *}$ & $0.834^{* * *}$ & $0.871^{* * *}$ & $0.864^{* * *}$ \\
Message \& Promise Condition & $(0.232)$ & $(0.233)$ & $(0.215)$ & $(0.215)$ \\
Promise made & & 0.127 & & -0.191 \\
& & $(0.421)$ & & $(0.323)$ \\
Constant & $4.115^{* * *}$ & $4.117^{* * *}$ & $5.366^{* * *}$ & $5.348^{* * *}$ \\
Log likelihood & $(0.924)$ & $(0.925)$ & $(0.923)$ & $(0.921)$ \\
Observations & -212.47 & -212.42 & -225.84 & -225.66 \\
Number of subjectID & 720 & 720 & 720 & 720 \\
\hline
\end{tabular}

Data from responders only

Includes (subject) random effects; robust standard errors (clustered by subject) in parentheses $* * * \mathrm{p}<0.1, * * \mathrm{p}<0.05, * \mathrm{p}<0.01$ 
Table 3. Regressions of proposer earnings
(1)
(2)
(3)
(4)
(5)
(6)

Dependent variable:

Earnings

High Stakes Conditions

Low Stakes Conditions

\begin{tabular}{|c|c|c|c|c|c|c|}
\hline Message Conditions & $\begin{array}{c}0.460 \\
(0.533)\end{array}$ & $\begin{array}{c}0.194 \\
(0.285)\end{array}$ & $\begin{array}{c}0.179 \\
(0.287)\end{array}$ & $\begin{array}{l}0.745^{* * *} \\
(0.323)\end{array}$ & $\begin{array}{c}0.202 \\
(0.303)\end{array}$ & $\begin{array}{c}0.222 \\
(0.316)\end{array}$ \\
\hline Promise Condition & $\begin{array}{l}-0.406 \\
(0.516)\end{array}$ & $\begin{array}{l}0.444^{* * *} \\
(0.261)\end{array}$ & $\begin{array}{l}0.468^{* * *} \\
(0.263)\end{array}$ & $\begin{array}{l}-0.269 \\
(0.283)\end{array}$ & $\begin{array}{l}0.0876 \\
(0.288)\end{array}$ & $\begin{array}{l}0.0834 \\
(0.290)\end{array}$ \\
\hline High Allocation & & $\begin{array}{l}8.638^{* * *} \\
(0.507)\end{array}$ & $\begin{array}{l}6.543^{* * *} \\
(0.921)\end{array}$ & & $\begin{array}{l}3.041^{* * *} \\
(0.388)\end{array}$ & $\begin{array}{l}2.124^{* * * *} \\
(0.659)\end{array}$ \\
\hline $\begin{array}{l}\text { Message Conditions } \\
\text { X High Allocation }\end{array}$ & & $\begin{array}{c}0.488 \\
(0.723)\end{array}$ & $\begin{array}{c}0.740 \\
(0.670)\end{array}$ & & $\begin{array}{l}0.968^{* * *} \\
(0.526)\end{array}$ & $\begin{array}{c}0.741 \\
(0.525)\end{array}$ \\
\hline $\begin{array}{l}\text { Promise Condition } \\
\text { X High Allocation }\end{array}$ & & $\begin{array}{c}-1.249^{* * *} \\
(0.758)\end{array}$ & $\begin{array}{c}-1.548^{* * *} \\
(0.729)\end{array}$ & & $\begin{array}{l}-0.406 \\
(0.469)\end{array}$ & $\begin{array}{l}-0.245 \\
(0.480)\end{array}$ \\
\hline SINS score & & & $\begin{array}{l}-0.0672 \\
(0.0820)\end{array}$ & & & $\begin{array}{l}-0.048 \\
(0.103)\end{array}$ \\
\hline $\begin{array}{l}\text { SINS score } \\
\text { X High Allocation }\end{array}$ & & & $\begin{array}{l}0.669^{* * *} \\
(0.256)\end{array}$ & & & $\begin{array}{c}0.376^{\text {*** }} \\
(0.194)\end{array}$ \\
\hline Constant & $\begin{array}{l}7.894^{* * *} \\
(0.367)\end{array}$ & $\begin{array}{l}3.863^{* * *} \\
(0.214)\end{array}$ & $\begin{array}{c}4.067^{* * *} \\
(0.368)\end{array}$ & $\begin{array}{l}5.325^{* * *} \\
(0.272)\end{array}$ & $\begin{array}{l}3.830^{* * *} \\
(0.235)\end{array}$ & $\begin{array}{l}3.952^{* * * *} \\
(0.309)\end{array}$ \\
\hline $\mathrm{R}^{2}$ & 0.001 & 0.603 & 0.609 & 0.009 & 0.298 & 0.304 \\
\hline Observations & 720 & 720 & 720 & 720 & 720 & 720 \\
\hline Number of subjectID & 72 & 72 & 72 & 72 & 72 & 72 \\
\hline
\end{tabular}

Data from proposers only

Includes (subject) random effects; robust standard errors (clustered by subject) in parentheses $* * * \mathrm{p}<0.1, * * \mathrm{p}<0.05, * \mathrm{p}<0.01$ 
Figure 1. Mean offers by condition and allocation size

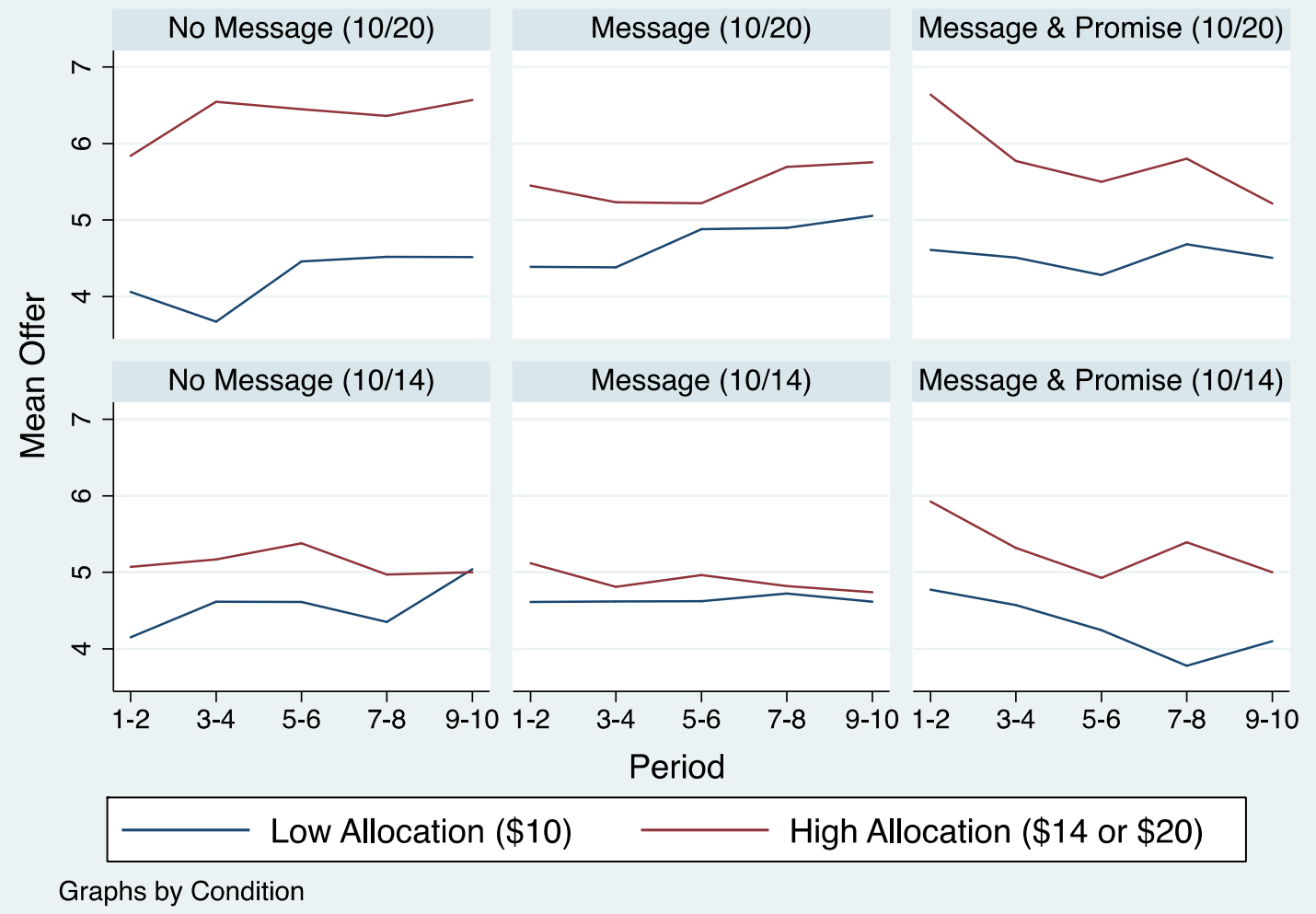


Figure 2A. Proposers' average offers by allocation size and condition (High Stakes)

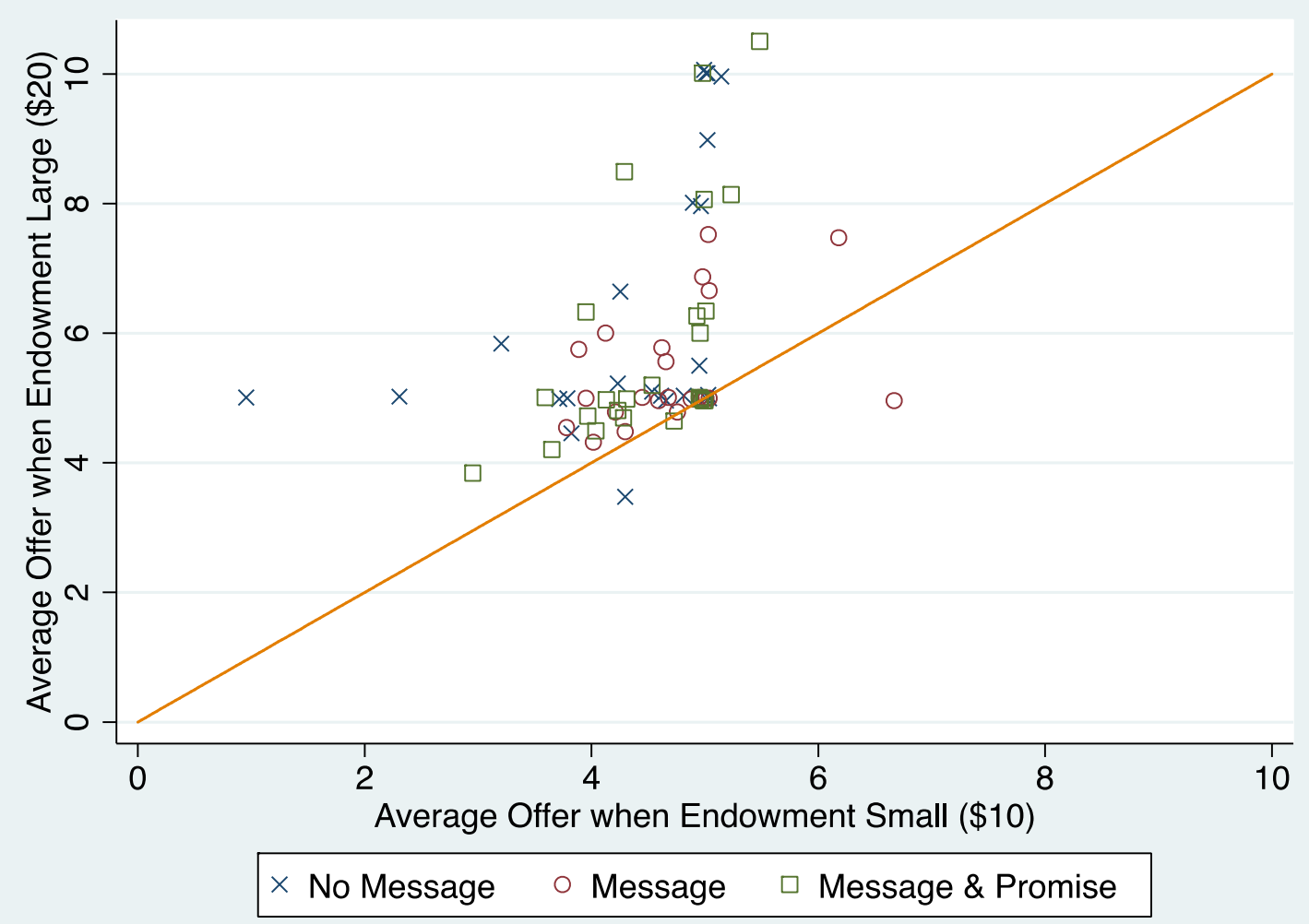

Figure 2B. Proposers' average offers by allocation size and condition (Low Stakes)

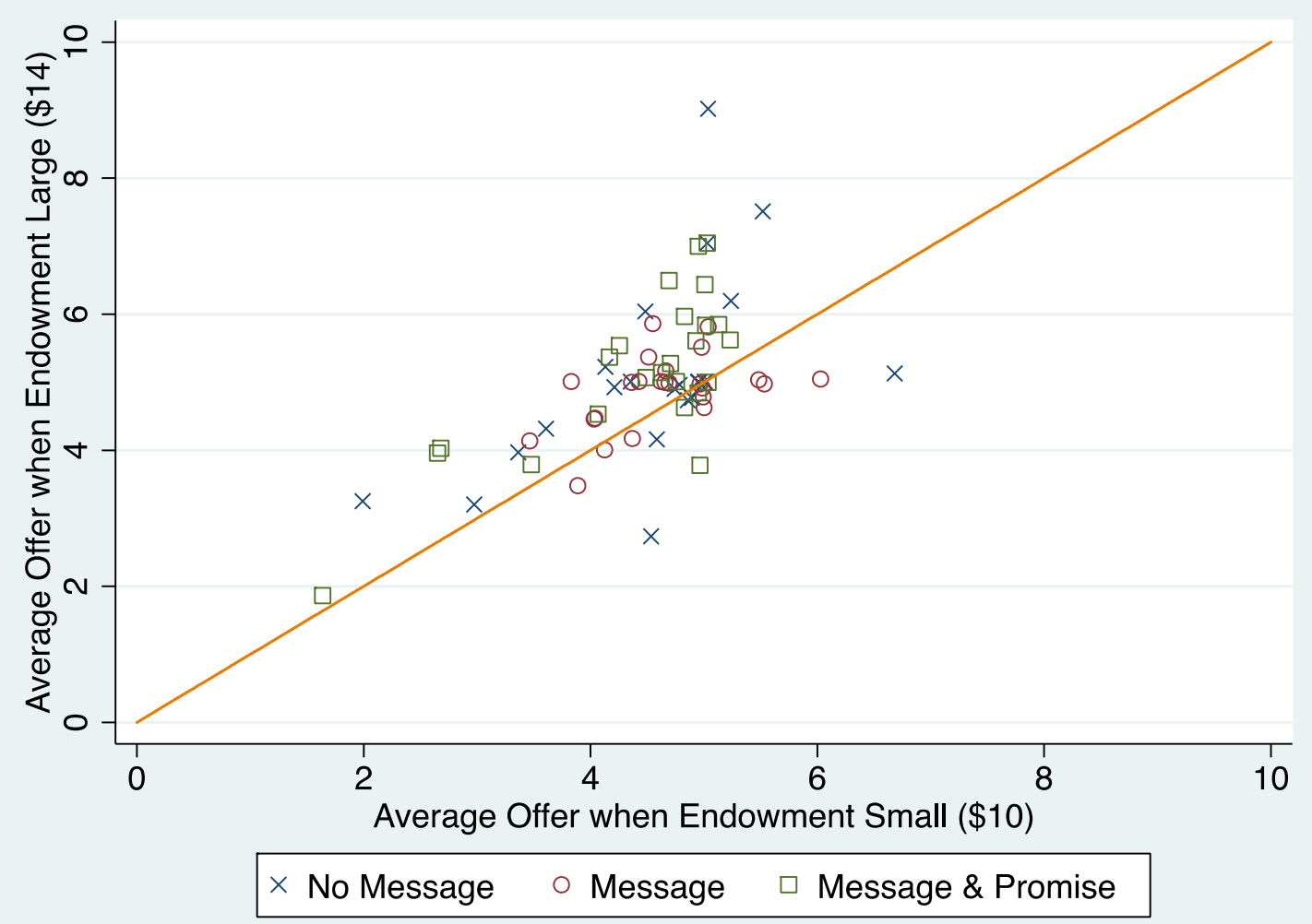


Figure 3. Proportions of Dishonest Messages and Promises by Condition

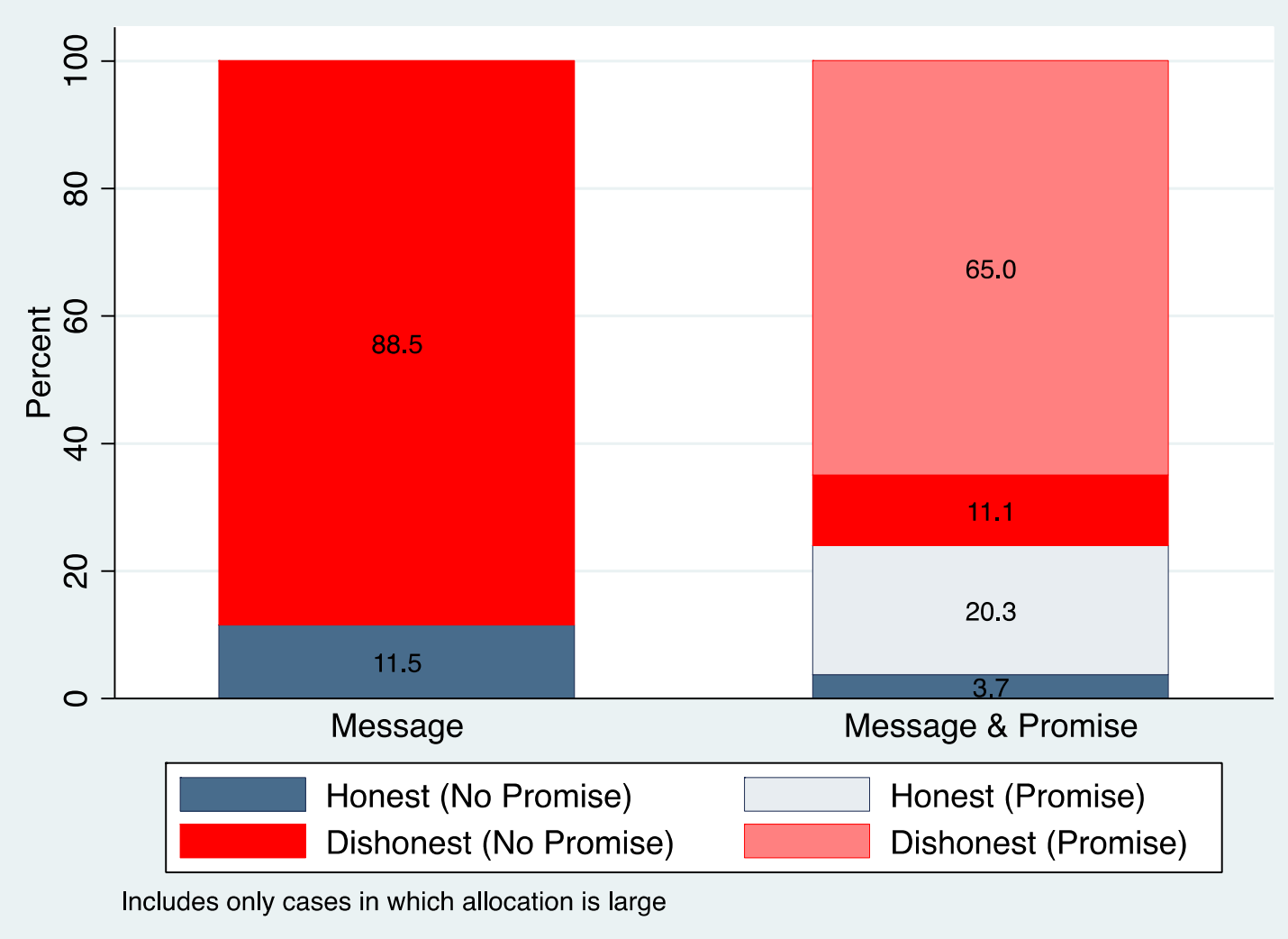

Figure 4. Offers by Message Sent and Condition

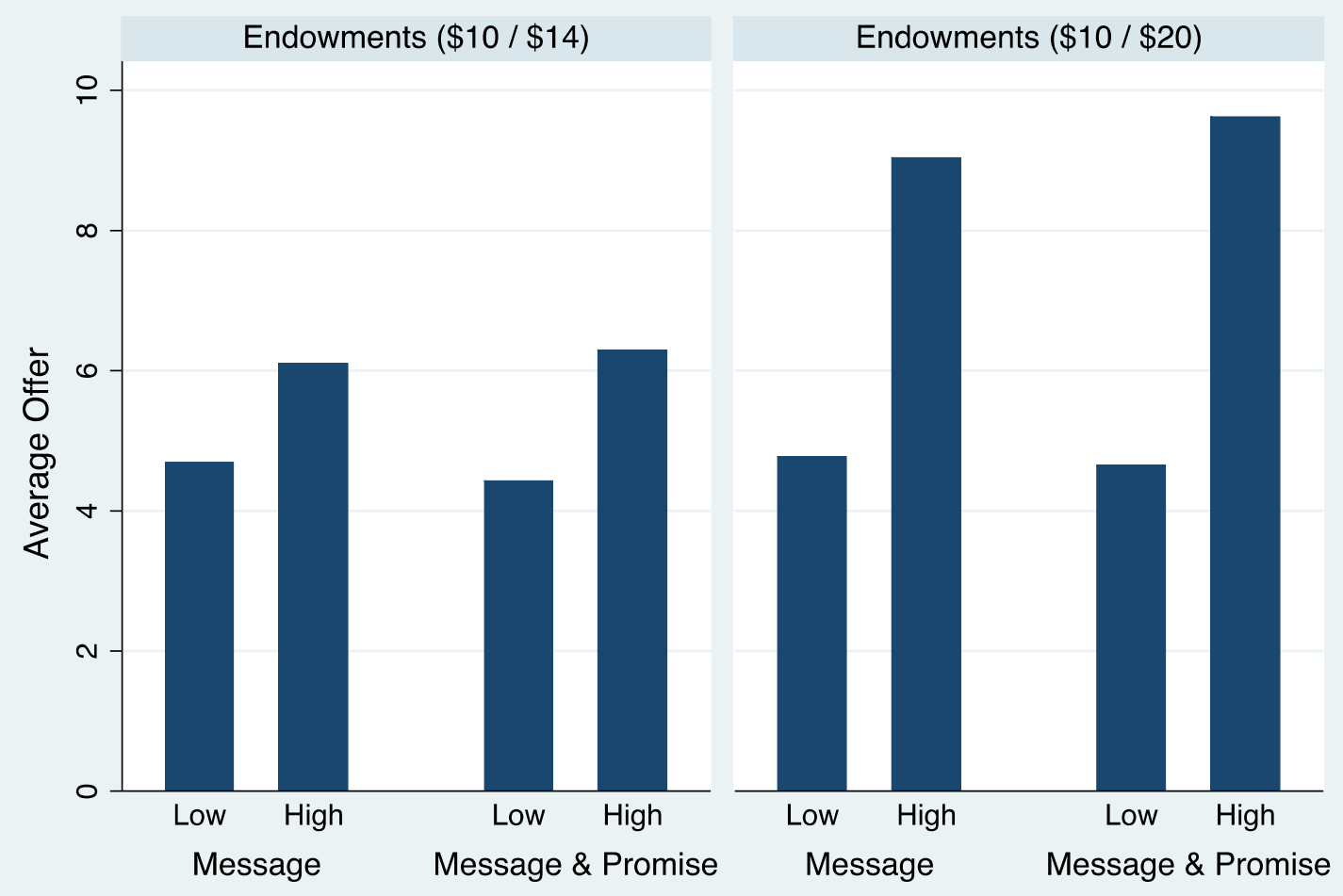

Low: message $=\$ 10 ;$ High: message $=\$ 14$ or $\$ 20$ 
Figure 5A. Rejection frequency by Offer Range and Condition (High Stakes)

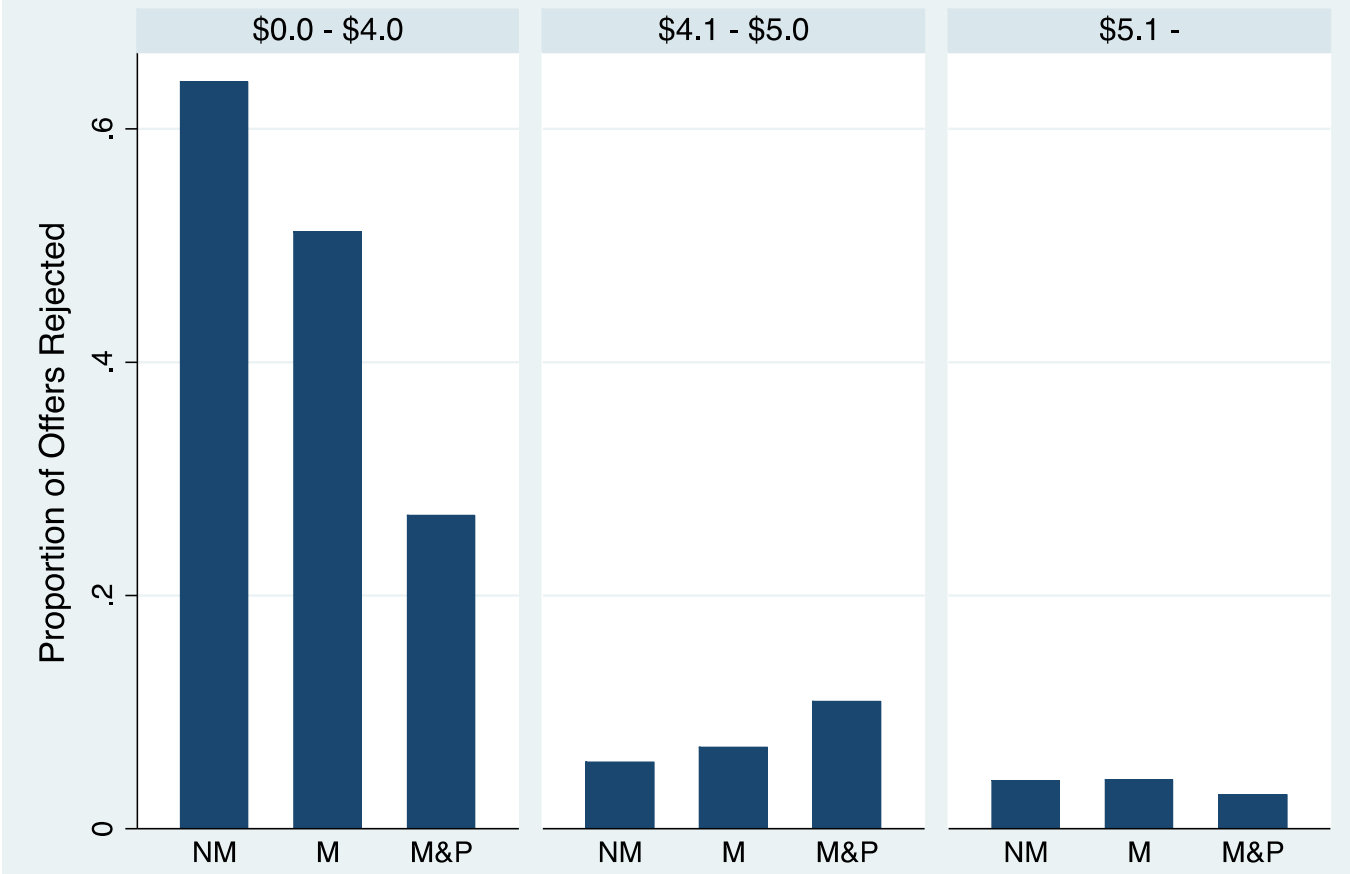

Graphs by Offer Range; High Stakes Conditions

Figure 5B. Rejection frequency by Offer Range and Condition (Low Stakes)

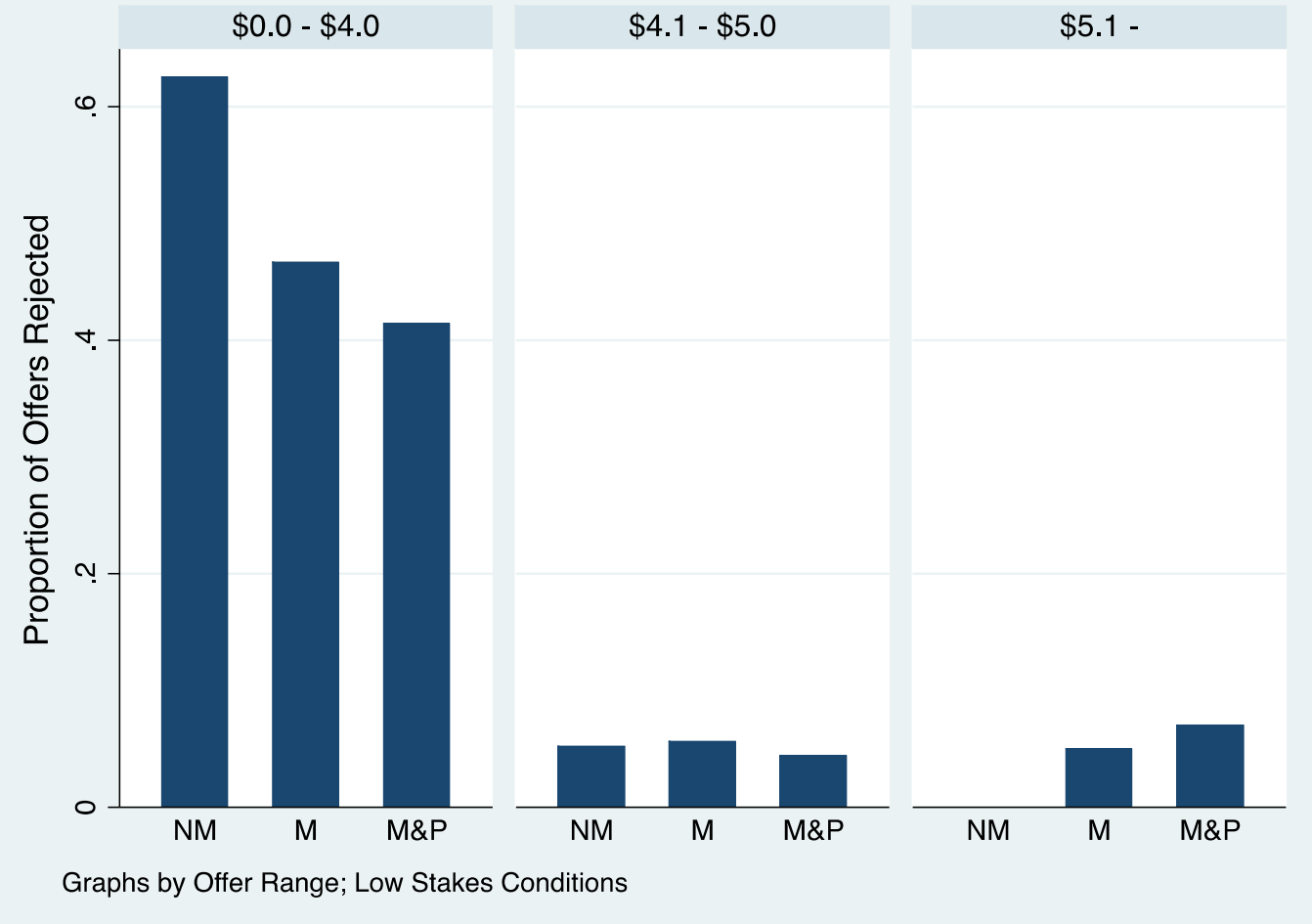


Figure 6. Mean proposer earnings by condition

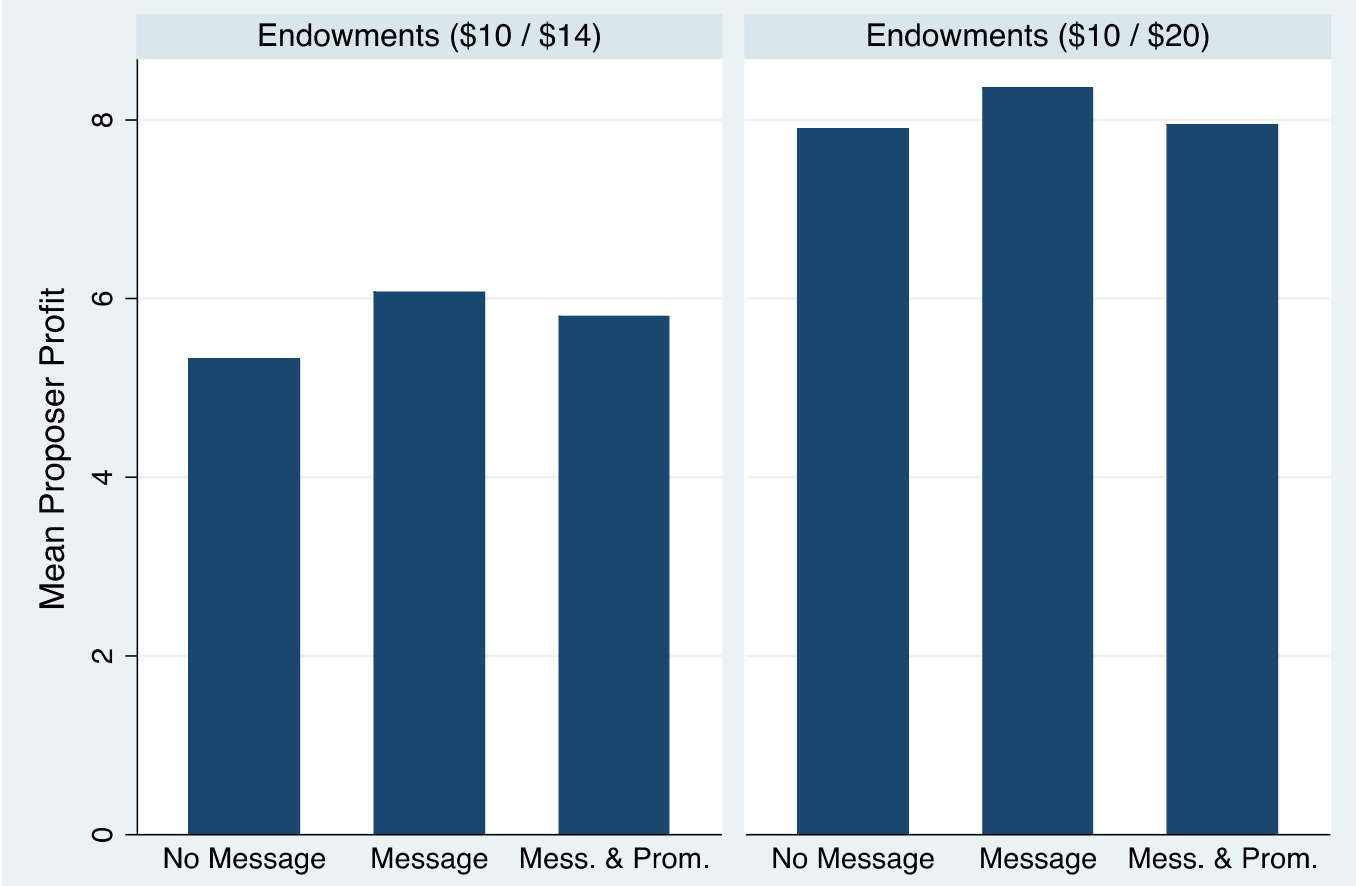

Graphs by TreatHighStake 


\section{Material for On-line Appendix: Additional Analysis}

\section{A1. Analysis of Individual Behavior}

Figures A1a and A1b show the average difference between offers made for the high allocation $\left(w=w_{H}\right)$ and low allocation $\left(w=w_{L}\right)$, calculated at the subject level and then averaged across subjects in a condition. In both High and Low stakes conditions, proposers' offers differ to a greater extent, indicating more informative offers, in the No Message and in the Message \& Promise conditions than in the Message condition.

We also explore behavior at the individual level by testing the extent to which each participant in the role of proposer offered different amounts for $w=w_{L}$ and for $w=$ $w_{H}$. For each condition, Table A1 reports the number and proportion of participants for whom we can statistically reject the null hypothesis, $x\left(w_{H}\right)=x\left(w_{L}\right)$, in favor of the alternative hypothesis, $x\left(w_{H}\right)>x\left(w_{L}\right)$, using a one-tailed t-test with the 10 offers made by that participant. That is, the table answers the question: How many proposers in each condition make offers that convey statistically reliable information about the allocation (even with small numbers of observations)?

Consistent with the analysis in the main text, a greater proportion of proposers' behavior conveys information about the allocation size in the No Message and Message \& Promise conditions than in the Message condition. Looking at the combined data, roughly five times as many proposers make significantly different offers in the former two conditions than in the latter. This difference is more extreme for High Stakes, but the pattern is also present in the Low Stakes conditions.

We next explore whether deceptive behavior correlates with individual characteristics, using a scale developed from the Self-Reported Inappropriate Negotiations Strategies survey (SINS; Robinson, et al., 2000), administered at the end of the experiment. The survey consists of ratings of the appropriateness of negotiation tactics, such as, "In return for concessions from your opponent now, offer to make future concessions which you know you will not follow through on." The survey has 30 items; however, we use a 7-item scale obtained by combining two sub-scales, relevant for our experiment, False Promises (3 items) and Misrepresentation (4 items). ${ }^{9}$

\footnotetext{
${ }^{9}$ We also conducted this analysis with the Mach-IV test of Machiavellianism (Christie and Geis, 1970), and particularly with the Positive Interpersonal and Negative Interpersonal sub-scales. We find qualitatively similar results to those we report here, particularly for the Positive Interpersonal scale.
} 
We divided proposers into those scoring above and below average on the SINS sub-scale, labeling them as "High SINS" and "Low SINS", respectively. Figures A2a and $\mathrm{A} 2 \mathrm{~b}$ are comparable to Figures A1a and A1b, examining these two subsamples separately. The figures reveal stronger offer differences for Low SINS proposers, who rate deceptive tactics as less appropriate. High SINS proposers generally engage in more misrepresentation across conditions, being thus less sensitive to the negotiation conditions. ${ }^{10}$ Of course, this part of our analysis is largely exploratory and requires further study before drawing definitive conclusions.

\section{A2. Analysis of Responder Earnings}

Figure A3 and Table A2 report analyses for responder earnings that correspond to those in Figure 6 and Table 3 in the paper. Figure A3 reveals that there are no substantial treatment differences in responder earnings, which is confirmed by models 1 and 3 in Table A2. As models 2 and 4 show, however, responders earn less of the high allocation in the message conditions and more in the Promise condition. These differences are inversely related to those in Table 3, which indicates that the Message condition shifts the high allocation surplus from the responders to the proposers, who are able to capture a greater share when they send messages. This is reversed when proposers can include promises with their messages. All of these effects are consistent with our analyses of proposer earnings and behavior.

\footnotetext{
${ }^{10}$ Regression analysis, not reported here, confirms that the interactions in Figures A1a and A1b are consistent across both High and Low stakes conditions, though they are larger and statistically significant only in the High stakes conditions.
} 
Table A1. Proportion of proposers making different offers by allocation

\begin{tabular}{|l|c|c|c|}
\hline & No Message & Message & $\begin{array}{c}\text { Message \& } \\
\text { Promise }\end{array}$ \\
\hline High Stakes $\mathbf{( \$ 1 0 / \$ 2 0 )}$ & $11(46 \%)$ & $1(4 \%)$ & $11(46 \%)$ \\
\hline Low Stakes $\mathbf{( \$ 1 0 / \$ 1 4 )}$ & $6(25 \%)$ & $3(13 \%)$ & $8(35 \%)^{\mathrm{a}}$ \\
\hline Combined & $17(35 \%)$ & $4(8 \%)$ & $19(40 \%)$ \\
\hline
\end{tabular}

Subjects classified by whether a t-test rejects $x\left(w_{H}\right)=x\left(w_{L}\right)$ in favor of $x\left(w_{H}\right)>=x\left(w_{L}\right)$.

Data from proposers only; data includes 24 participants per condition, except for $\left(^{\mathrm{a}}\right)$ where one subject was omitted because $w=w_{L}$ only once in the 10 periods.

Table A2. Regressions of responder earnings
(1)
(2)
(3)
(4)

Dependent variable: earnings

High Stakes Conditions $\quad$ Low Stakes Conditions

\begin{tabular}{lcccc}
\hline Message Conditions & -0.210 & 0.499 & 0.0554 & 0.140 \\
& $(0.243)$ & $(0.317)$ & $(0.221)$ & $(0.294)$ \\
Promise Condition & 0.031 & -0.111 & 0.152 & -0.149 \\
& $(0.222)$ & $(0.288)$ & $(0.225)$ & $(0.298)$ \\
High Allocation & & $2.607^{* * *}$ & & $0.813^{* * *}$ \\
Message Conditions X High & & $(0.326)$ & & $(0.308)$ \\
Allocation & & $-1.528^{* * *}$ & & -0.192 \\
Promise Condition X High & & $0.401)$ & & $(0.371)$ \\
Allocation & & $(0.352)$ & & $0.700^{* * *}$ \\
Constant & $4.690^{* * *}$ & $3.473^{* * *}$ & $4.108^{* * * *}$ & $3.708^{* * *}$ \\
& $(0.213)$ & $(0.255)$ & $(0.159)$ & $(0.196)$ \\
$\mathrm{R}^{2}$ & 0.001 & 0.130 & 0.002 & 0.047 \\
& & & & \\
Observations & 720 & 720 & 720 & 720 \\
Number of subjectID & 72 & 72 & 72 & 72 \\
\hline
\end{tabular}

Data from responders only

Includes (subject) random effects; robust standard errors (clustered by subject) in parentheses $* * * \mathrm{p}<0.1, * * \mathrm{p}<0.05, * \mathrm{p}<0.01$ 
Figure A1a. Mean difference between offers for high and low allocations (High Stakes)

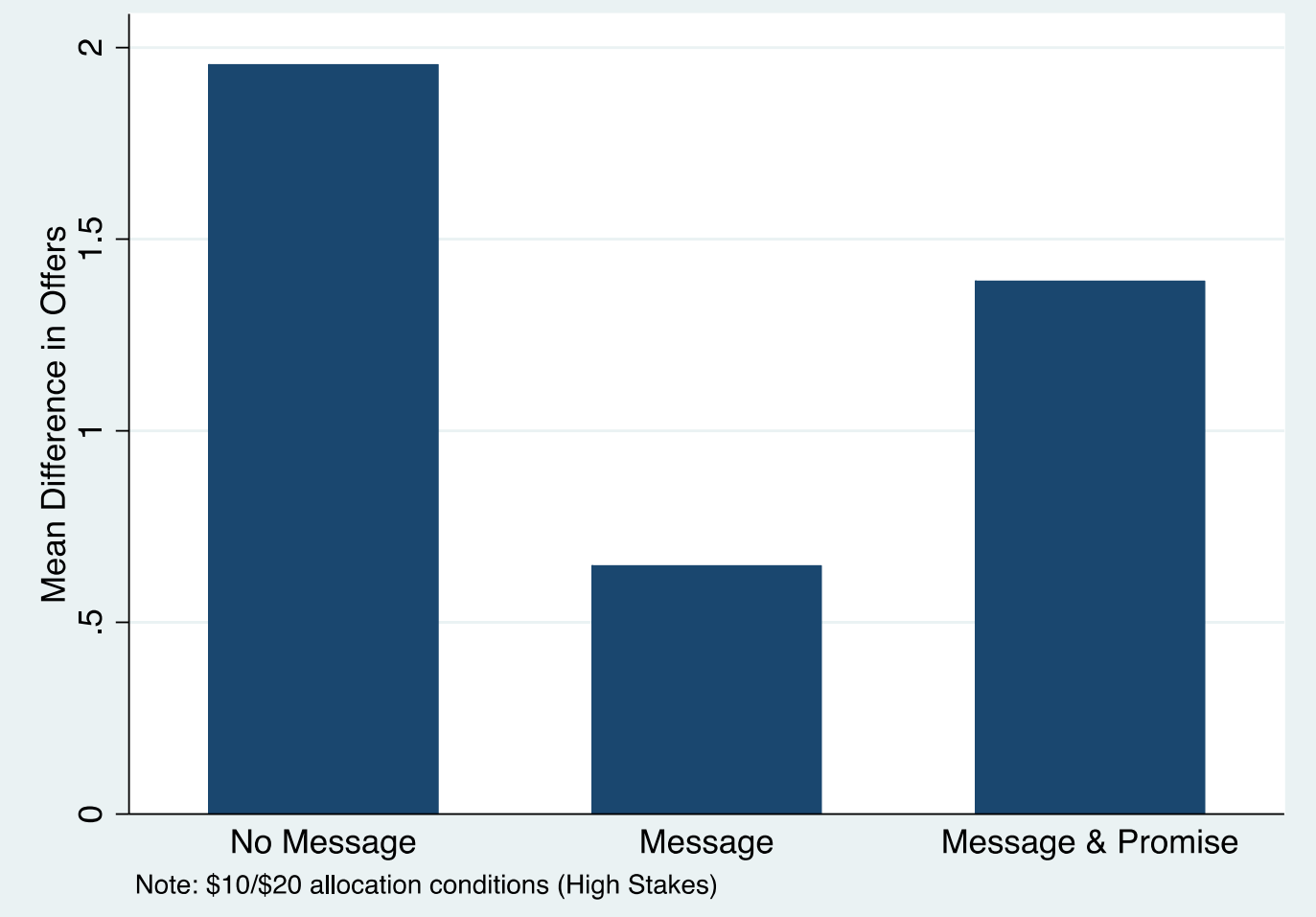

Figure A1b. Mean difference between offers for high and low allocations (Low Stakes)

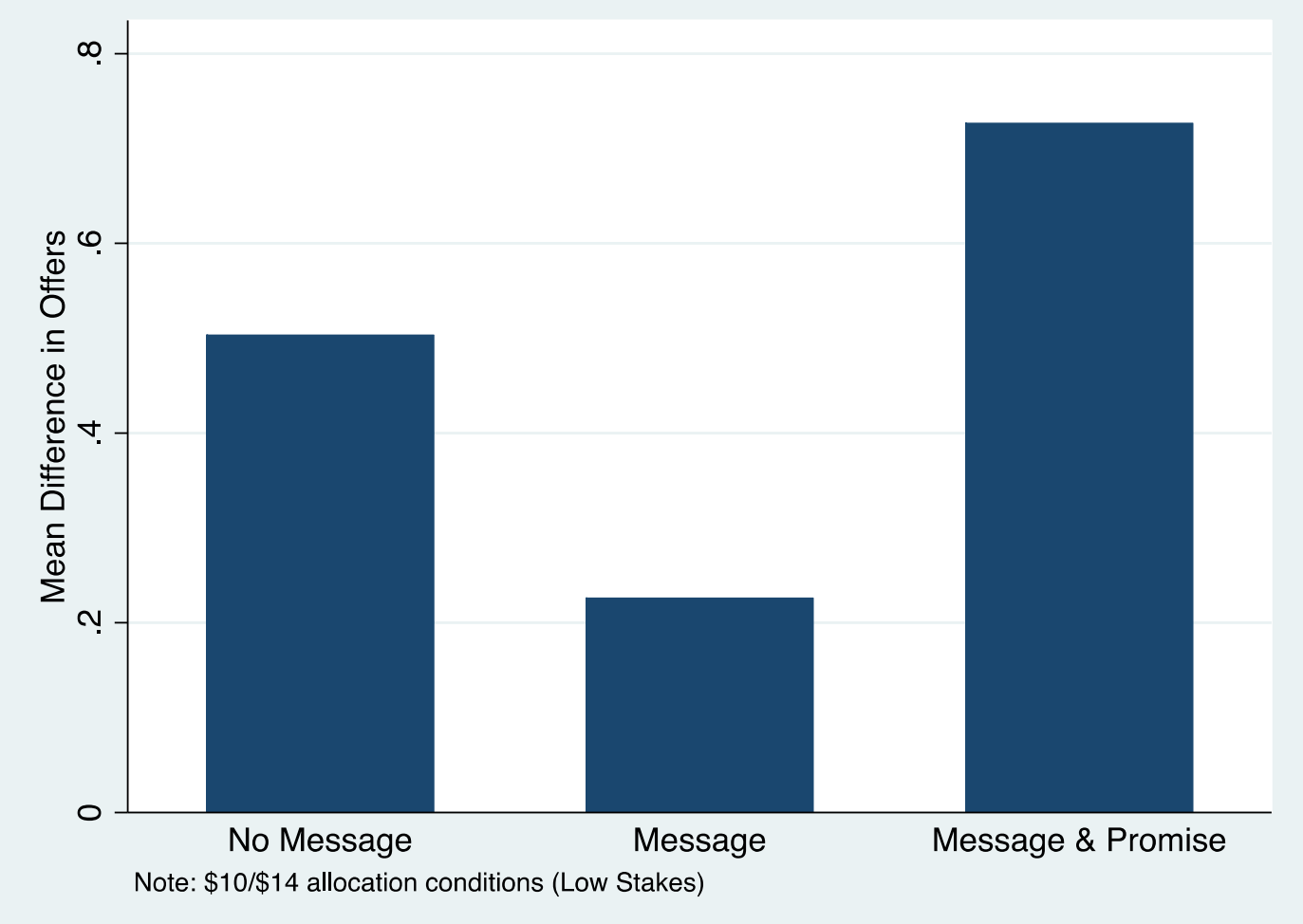


Figure A2a. Mean Offer Difference between Low and High Allocations by Condition and SINS score (High Stakes)

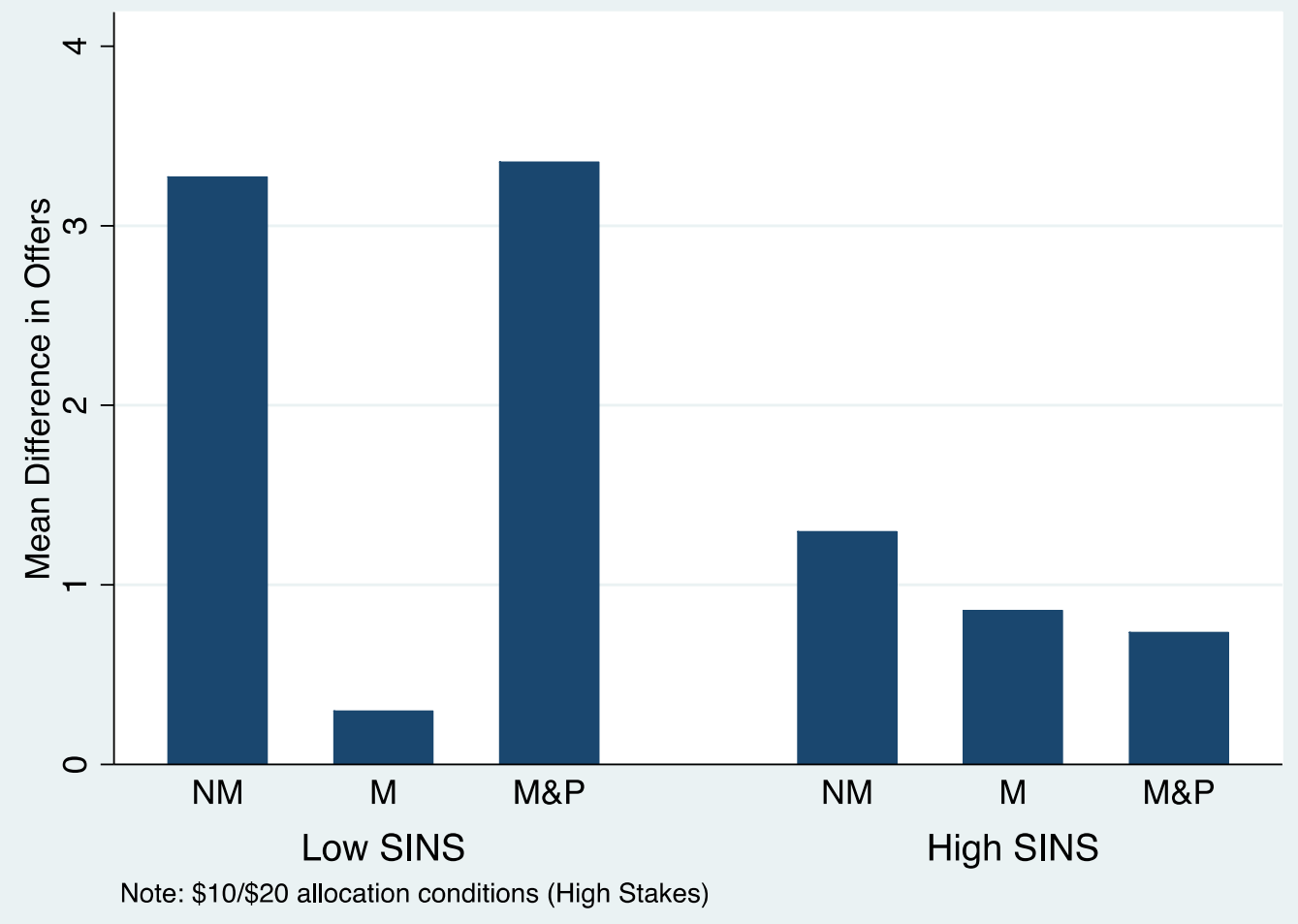

Figure A2b. Mean Offer Difference between Low and High Allocations by Condition and SINS score (Low Stakes)

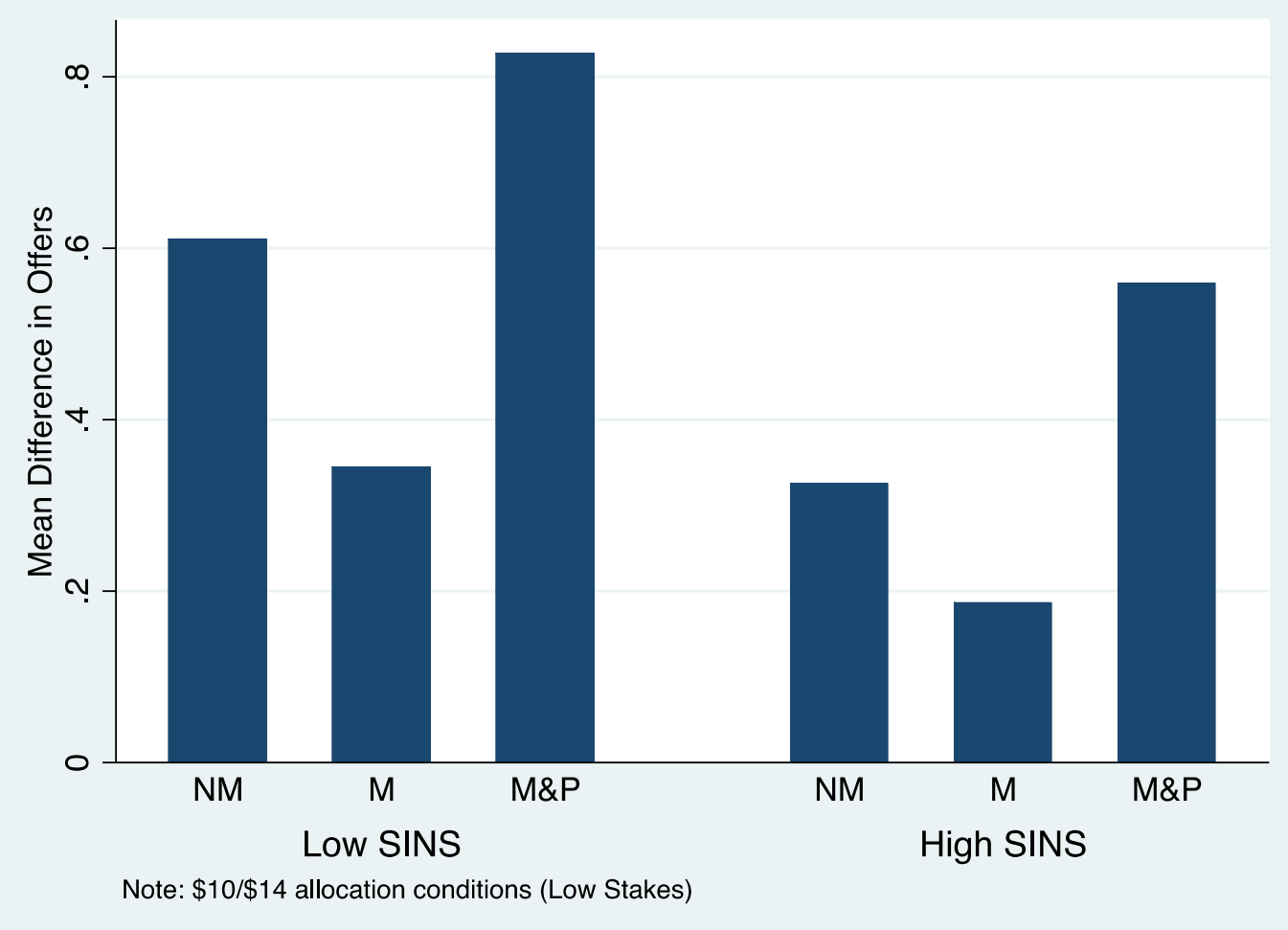


Figure A3. Mean responder earnings by condition

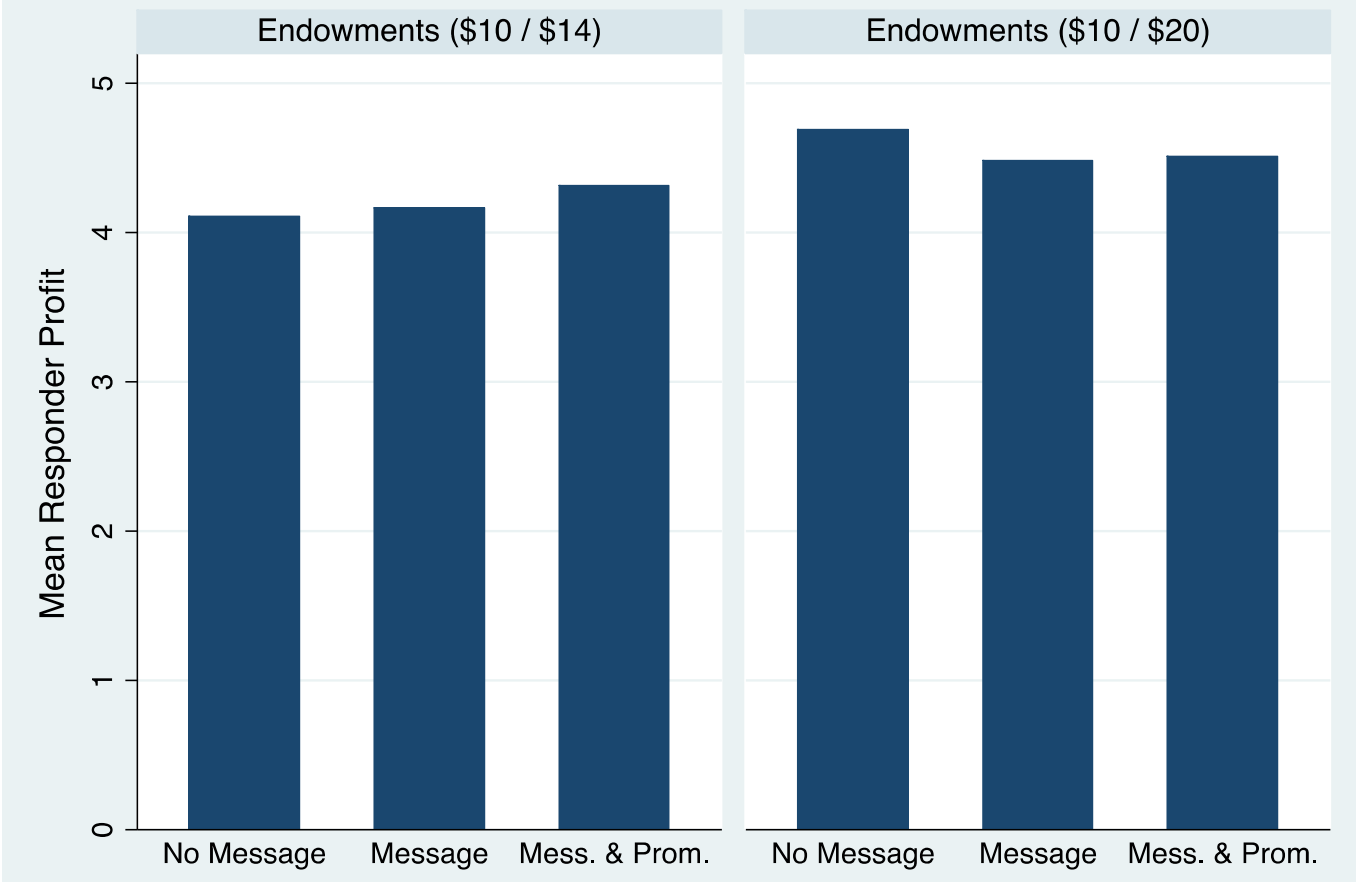

Graphs by TreatHighStake 